\title{
PODE A LITERATURA SER UM MESTRE?
}

$\operatorname{Vilmar} \operatorname{Martins}^{(*)}$

\section{O QUE É UM MESTRE?}

Mestre: advindo do latim Magister este substantivo caracteriza dentre muitos significados: aquele que ensina. Mesmo sendo concebível pensar um mestre sem discípulo, é uma contradição lógica pensar um mestre que não exerça a mestria e esta se dá em uma relação.

Distante de questões metafisicas, pressuponho que não há algo no mestre que prescinda a relação de mestria, sendo assim minha pergunta não busca uma substancialidade do ser mestre, mas sim o que é agenciado nesta relação que faz com que um dos sujeitos se porte enquanto mestre.

A questão inicial: o que é um mestre? Se reconfigura em: o que autoriza alguém a ser um mestre? Esta pergunta simples e ao mesmo tempo provocadora, assume ares impossíveis quando pensada a partir dos seus adjetivos de relação: O que autoriza, permite, consente, faculta, garante, enseja, qualifica, credencia, possibilita, habilita, legitima alguém a ser um mestre?

Adentrar a essa adjetivação seria adentrar em um labirinto sem o auxilio de Ariadne, sendo assim, antes de me aventurar, traçarei minha guia nesses caminhos tortuosos. Inicialmente simplifico a questão: "O que dá a um homem ou a uma mulher o poder de ensinar a um outro ser humano, de onde provém essa autoridade?” (STEINER, 2018, p. 11).

$\mathrm{O}$ ato de ensinar, a performance pedagógica, acompanha o tipo humano desde os seus primórdios, é inconcebível um agrupamento humano que prescinda de atos de ensino.

A performance pedagógica articula sujeitos enquanto mestres e discípulos. Ainda que esta relação nem sempre se apresente de forma estanque é possível afirmar que em um ato de ensino temos aquele que ensina e aquele que aprende.

Como observado acima, os adjetivos que mediam essa relação podem ser os mais distintos, porém, apesar da fluidez desse encontro, o mesmo ocorre e é imprescindível para a sociabilidade humana.

Essa relação - como toda relação humana - não se dá de forma harmoniosa e nem os papeis são desempenhados sempre a contento. Há mestres que julgam que seus discípulos não estão à altura dos seus ensinamentos e por isso os abandonam, e da mesma forma há discípulos que

\footnotetext{
${ }^{(*)}$ Doutor em Educação pelo PPGE/UFSC. Orcid: 〈http://orcid.org/0000-0002-3875-5340〉. E-mail: vilmarmartins @hotmail.com.
} 
acreditam terem ultrapassado seus mestres e deixam ou traem os mesmos para realizarem-se, muitas vezes como novos mestres.

Sendo assim Steiner (2018), pensa três cenários para esta relação: haveriam os mestres que destroem seus discípulos; os discípulos que traem seus mestres e por fim uma troca baseada no respeito mútuo.

Nesta relação dialógica e dialética, repleta de continuidades e rupturas, traçarei meu fio em direção ao mestre, mesmo sabendo que a figura do mestre é agenciada pelo discípulo, na inexistência do discípulo soa ilógico falar em mestre - apesar de ser concebível um mestre sem discípulos.

O mestre, configurado como aquele que detém o conhecimento, a revelação, a chave decifradora dos mistérios, a expertise para a solução do problema, o know how que permite a ação, a maior experiência, a vivência daquilo que partilha, a transcendência, etc.

\section{PARA QUE PRECISAMOS DE UM MESTRE?}

Assim como os adjetivos de relação, aquilo que caracteriza um mestre se apresenta nas suas mais diferentes configurações. Porém, podemos não podemos negar que o mestre é detentor de algo que falta ao discípulo, ou, o mestre é aquele que possibilita ao discípulo realizar algo que sozinho o mesmo não realizaria.

Novos elementos surgem e chegamos em um ponto crucial neste labirinto: afinal para que precisamos de um mestre? Nietzsche em sua obra Crepúsculo dos ídolos, elenca três atividades para as quais necessitamos de mestres / educadores (Erzieher): "Deve-se aprender a ver, aprender a pensar, aprender a falar e escrever: o objetivo, nos três casos, é uma cultura nobre." (NIETZSCHE, 2017, p. 48).

$\mathrm{Na}$ sequência do texto o filósofo delimita, porque aprender a ver e pensar. Aprender a ver demorando o olhar, com sossego, paciência, lentamente, recalcitrante. O objetivo ao refrear o ímpeto do olhar é abster-se de rapidamente se comprometer com os impulsos e os estímulos, não reagir. Espiritualizar o olhar com a demora, atentando para as nuances e assim permitir que o novo se apresente.

Aprender a pensar, com o esforço necessário para gestar os pensamentos como dança. $\mathrm{O}$ pensamento necessita ser cultivado, aprendido, a partir de técnicas, planos de estudos e mestria. O objetivo de cultivar o pensamento é engendrar pensamentos que possibilitem uma autêntica 
experiência de pensar. Assim como na dança, onde os movimentos ritmados, repetidos e mecânicos, soam naturais e graciosos, como se não houvesse esforço por trás de cada passo, o pensamento também deve se apresentar como natural, porém gestado a partir de grande esforço.

Ainda que o texto não especifique o aprender a falar e a escrever, outros textos do filósofo esclarecem melhor essa questão.

Falar e escrever são entendidas como uma única atividade, desta forma um mestre que nos ensine a falar, certamente nos ensinará a escrever, não porque escreveremos o que falamos, mas sim porque dado o caráter performativo da linguagem o estilo da fala pode ser transposto para a escrita e vice-versa.

Aprender falar, sem tagarelice é um desafio, pois somos sujeitos verborrágicos, muitos dos nossos valores e experiências são determinados pelas palavras. Onde havia um encontro com a vida, colocamos uma palavra e para expressar este encontro vulgarizamos nossas vivências transmitindo os mesmos com palavras gregárias e mortas. "Em toda fala há um grão de desprezo" (p. 64). Sendo assim importa aprender uma fala cantante, como um coro dionisíaco que ao mesmo tempo em que expressa, demonstra nossas vivências mais intimas.

Da mesma forma ocorre com o escrever. Aprender a escrever com uma escrita visceral, que exija esforço, desnudando nossa alma a partir do acúmulo de trabalho e dedicação. "Escreve com sangue; e aprenderás que sangue é espírito". (NIETZSCHE, 2011, p. 40). Longe da esperança em lapsos criativos, sangrar na escrita só ocorre após o acúmulo de ideias, estudos, leituras e vivências. Represar, para depois irromper - eis uma escrita com sangue.

Há uma correlação e um objetivo comum entre as 03 atividades para as quais precisamos de um mestre - ver, pensar, falar e escrever - a correlação consiste na demora e o no acúmulo, a não ação imediata, pressupondo uma outra relação para com a vida; o objetivo nas três atividades é espiritualizar a existência, criando uma cultura nobre.

Agora sabemos da necessidade de um mestre, mas qual mestre?

\section{QUAIS AS CARACTERÍSTICAS DE UM MESTRE?}

Tecendo meu fio de Ariadne, parti do que é um mestre, para o que autoriza alguém a ser um mestre, passando pela necessidade de mestria e agora chego as suas características. Ao mesmo tempo em que puxo o traço das características de um mestre adiciono um novo traço entrelaçando os dois fios ao me perguntar: pode a literatura ser um mestre? 
Steiner em sua obra Lições dos mestres, elenca uma série de relações de mestria e nos apresenta algumas características de mestres.

Uma primeira característica do mestre é o exemplo. Não podemos negar que uma das fontes da "[...] autoridade didática, é o exemplo". (STEINER, 2018, p. 13). Dos mestres filósofos aos mestres religiosos, não são poucos os que buscam apresentar suas vidas como exemplos a serem seguidos. O discípulo se relaciona com o mestre a partir da imitação.

Na sua atuação como exemplo o mestre não media o conteúdo, ele é o próprio conteúdo da performance: "[...] a única coisa que pode produzir frutos é um ensino verdadeiro, um ensino feito pelo e para o espirito, dirigido à pessoa como um todo, um ensino de vida" (p. 105).

A literatura é infinda no oferecimento de mestres a serem seguidos, desde os personagens que articula, passando pelo estilo, até mesmo seus autores servem como exemplo. Mesmo incapaz de - salvo exceções - ao mesmo tempo em que media ser o conteúdo mediado, a literatura enquanto exemplo está apta a exercer o papel de mestre.

Além do exemplo, os mestres muitas vezes “despertam o dom” em seus discípulos e “[...] colocam a obsessão em seu caminho" (p. 27). Ao direcionar os discípulos a certas tarefas, auxiliando os mesmos a encontrarem seus objetivos existenciais, o mestre desperta algo que já existe em seus discípulos. "O mestre induz a visões que são, na verdade, re-visões e déjà-vus" (p. 37).. Essa obsessão se torna a razão de vida do discípulo e o escopo no qual o mesmo irá se realizar.

Da mesma forma age a literatura, fora de um estrato metafisico posso argumentar que a literatura engendra algo que já existe no leitor. Despertando o que já está em forma latente e direcionando o leitor a realizá-lo. Na interação com a literatura, muitas vezes ao acompanhar as ações dos personagens, observamos insights para a nossa própria vida. Partindo do pressuposto que o direcionamento existencial é uma das tarefas do mestre, certamente que a literatura realiza essa tarefa.

Outra característica do mestre é a persuasão "[...] a força básica do ensino é a persuasão. $\mathrm{O}$ professor solicita atenção, concordância, e na melhor das hipóteses, a discordância colaboradora" (p. 33). Este poder de direcionar as vontades e os desejos muitas vezes determina a diferença entre um bom e um péssimo mestre. Um mestre pouco convincente certamente deixa a desejar.

Neste processo de direcionamento, ao dirigir-se para o mais íntimo dos discípulos - o espírito - o mestre age enquanto sedutor. "É um composto indefinível, espiritual e carnal. O discípulo consome-se de desejo pelo seu mestre" (p. 32). A persuasão leva o mestre a jogar com o 
desejo do discípulo, fazendo com que o mesmo se volte para a sua vontade, os riscos e os privilégios neste jogo são infindos.

A literatura persuade? Indubitavelmente. Assim como mestre a boa e a péssima literatura podem ser divididas entre convincente ou não. Quando a literatura exerce seu poder de convencimento, este é avassalador. Direcionando vontades, desejos e vidas a obra convincente nos transforma.

Eis uma outra característica da mestria: "O contato com o mestre transforma vidas” (p. 119). É concebível, porém uma negação lógica, passar por um processo de discipulado e permanecer o mesmo. Caso isso ocorra, um dos sujeitos dessa relação não cumpriu o seu papel, ou não fomos bons discípulos, ou não tivemos bons mestre.

Para além do conjunto de ações da mestria, apenas desfrutar da presença do mestre já é um privilégio: “[...] somente privilegiados podem participar dessa jornada sabendo que ela os deixará transformados" (p. 61). A mestria é por natureza aristocrática. A popularidade do mestre não vulgariza o sentimento de privilégio da sua presença transformadora.

Ainda que não possua uma presença tão carismática quanto uma pessoa, a literatura transforma vidas. Certamente que o efeito não se repete de caso para caso - salvo exceções - mas, ao exercer sua mestria a literatura digna desse nome, em um processo de discipulamento modifica as existências com as quais interage. Até mesmo a popularidade de certas literaturas não diminui a sensação de privilégio que acompanha a sua compreensão.

O mestre mesmo ausente se faz presente no discípulo: 'Ele é para mim uma espécie de vigia, um corpo de ideias que me observa constantemente - alguém que tem minha custodia e que me vigia todo o tempo, um corpo de ideias pelo qual me sinto sendo observado" (p. 92). O compromisso com o mestre faz com que a mestria não se encerre com a ausência do mestre.

Os efeitos dos ensinamentos do mestre permanecem mesmo com sua ausência. Da mesma forma a literatura não interrompe seu efeito finda a sua leitura, mas continua reverberando, muitas vezes em novas compreensões.

O mestre fala de forma inesgotável, por isso a compreensão sempre se renova. As lições que os mestres nos deixam, com suas parábolas e mitos permanecem sempre em aberto, permitindo infindáveis interpretações. A abertura de significado dessas questões. "Provocam uma desestabilização na alma humana. Escapam à nossa capacidade de parafraseá-las e de compreendêlas, mesmo quando nos sentimos a ponto de captá-las” (p. 41). 
Muitos ensinamentos de mestres clássicos se imortalizaram na forma de literatura. A mesma parábola contada e recontada por mais de 20 séculos continua a reverberar significados ainda hoje. Ao dialogar com a nossa sede de significados, a fome da alma e do intelecto, por sentido a literatura se apresenta como fonte inesgotável de interpretação. Sendo assim, se o mestre é caracterizado por uma emanação de significados que não se esgota, a literatura é um mestre por excelência.

Isso que permanece, mesmo na fugacidade da nossa existência se relaciona com outra característica dos mestres, pois: “Os mestres são os guardiões e os transmissores da memória, que é a mãe de todas as musas" (p. 147). Os mestres representam uma tradição - mesmo quando resistem a tradição vigente - é da natureza do mestre fundar ou inserir-se em uma tradição.

Os discípulos ao promoverem os ensinamentos do mestre, aprimoram ou rejeitam - muitas vezes deturpam - certas questões, mas acabam sempre por presentificar o passado, na forma dos ensinamentos do mestre.

Este culto a mãe de todas as musas é muito bem exercido pela literatura. A memória é preservada na obra literária e ao ser lida é ressignificada e renovada. Em sua atividade de mestria a literatura também rede culto a memória.

O mestre busca realizar em seu discípulo algo que se situa para além dele. "O trabalho do grande mestre [...] eterniza não apenas o indivíduo como também a espécie humana" (p. 59). A matéria utilizada pelo mestre no direcionamento para este além, são as potencialidades dos seus discípulos, por isso: "O mestre une o seu melhor com o melhor do seu discípulo" (p. 134).

Em última instância: "O mestre nos dá confiança para nos tornar o que nós somos” (p. 135), não realizando a sua natureza nos seus discípulos, mas permitindo que os mesmos se realizem. Por isso muitas vezes: "O mestre ajuda os discípulos a seguirem na direção de uma luz que não lhe é possível atingir" (p. 58). Realizar-se nos discípulos, esta é muitas vezes a sina do mestre. Imortalizado em seus discípulos o mestre cumpriu o seu papel.

Ao realizar a sua mestria a literatura nos permite o contato com o que há de mais individual e ao mesmo tempo mais coletivo em nós, a nossa condição humanidade. Observar o desenrolar das tramas na literatura, nos leva melhor compreender as nossas potencialidades, não apenas como humanos, mas como indivíduos. Por mais contraditório que se assemelhe ao nos apresentar o outro a literatura permite o encontro com nós mesmos.

O mestre desperta em nós forças e impulsos nunca divisados. "O mestre nos lança em um movimento ascendente e transgressor" (p. 111). Diante do mestre corrompemos nossa condição 
anterior a mestria e nos lançamos na direção que o mestre aponta. Haverá maior legado de um mestre do que deixar uma atividade a ser realizada, uma dúvida a ser preenchida, um problema a ser resolvido?

Nem só de ensinamentos e direcionamentos é composta a mestria. Muitas vezes o mestre desperta dúvidas. "Seu objetivo é deflagrar no interlocutor um processo de incerteza, um processo de indagação que se aprofunda e leva um processo de autoindagação" (p. 35). O bom mestre ensina os seus discípulos a divergir, preparando os mesmos para se libertarem do mestre.

A apoteose do mestre. "O verdadeiro triunfo do mestre, ainda que nem sempre reconhecido, é ser refutado e ultrapassado pela descoberta de seu discípulo. É discernir em seu aluno uma força e um potencial de futuro que excedem os seus" (p. 160). Penoso é o exercício da mestria e qual a sua recompensa? A superação, refutação, o ser ultrapassado pelos discípulos que se libertam do mestre.

Essa libertação implica em uma espécie de ingratidão. "O mestre doa algo que será por fim desprezado" (p. 115). Superar o mestre, não permanecer sempre discípulo, eis a melhor forma de honrar o mestre.

A transgressão ascendente, a dúvida motivadora, a libertação na superação, acaso não são estes elementos humanos propiciados pela literatura?

A literatura desestrutura nossas significações, estremecendo nossos valores mais arraigados. Acaso não é este o papel do mestre? A obra literária nos possibilita superar - ainda que simbolicamente - as situações descritas em suas páginas. Mediar uma superação, como ensaio para a vida, acaso não é isso que um mestre faz?

Finda a leitura o livro volta para a estante. Ainda que sua presença permaneça nas significações e nas transformações que possibilitou e possibilitará a literatura em sua mestria age como o bom mestre, no final da lição despede o discípulo para que este pratique, aprimore, rejeite, até mesmo deturpe a lição aprendida. Sem esquecer que "O verdadeiro mestre deve, no final, estar só” (p. 102).

\section{COMO UM MESTRE ENSINA?}

Revejo minha tessitura, reservo fios para uso futuro, junto traços, observo as linhas "o que, para que, quais" e adiciono o "como", prossigo... 
No ensino o mestre transmite algo para o discípulo. Nada mais aberto e amplo do que uma transmissão, não é um acaso que os termos transmissão, transgressão, traição, tradução e tradição possuem as mesmas raízes.

Conforme apresentado acima a partir de Steiner (20018) a ação do mestre faz uso de muitos verbos: exemplificar, despertar, persuadir, direcionar, transformar, desestabilizar, desafiar, transmitir, representar, realizar, doar, ajudar, lançar, legar, potencializar, libertar, construir, mediar, etc.

Não haveria uma forma do mestre agir, muito menos garantias de sucesso nesta ação, porém a ação de mestria implica em responsabilidade, pois: "O verdadeiro magistério pode ser um empreendimento terrivelmente perigoso. $\mathrm{O}$ mestre tem nas mãos algo muito íntimo de seus alunos: a matéria frágil e inflamável de suas possibilidades" (p. 102).

O mestre tem ao seu dispor o espírito vivo dos seus discípulos. Ele toca e molda a própria vitalidade do humano, as raízes mais intimas do seu ser. Essa invasão muitas vezes necessita destruir para novamente reconstruir, por isso a responsabilidade do mestre. "Ensinar sem grave apreensão, sem uma reverência inquietante pelos riscos envolvidos, é uma frivolidade. Fazê-lo sem se preocupar com quais podem ser as consequências individuais e sociais é cegueira" (p. 102).

Porém, não nos esqueçamos que muitos mestres são gentis coveiros, onde todos seus esforços - ou a falta de esforços - se voltam para adormecer os espíritos e o interesse dos seus discípulos, reduzindo tudo a tédio, enfado, indiferença e cinismo. "O mau ensino é, quase literalmente, assassino e, metaforicamente, um pecado. Ele diminui o aluno, reduz a uma insanidade abjeto o assunto apresentado" (p. 26).

Atento aos bons e péssimos mestres, volto a provocação nietzschiana da necessidade de mestres e novamente questiono: como a literatura pode nos ensinar a ver, pensar, falar e escrever?

Penso que é possível observar características de mestria na obra $A h$, é? de Dalton Trevisan (2013), de tal forma que a mesma possa nos ensinar a ver, pensar, falar e escrever nos moldes nietzschianos.

Dalton Trevisan é um recluso e emblemático escritor curitibano, com mais de 50 obras publicadas, algumas destas traduzidas para quase uma dezena de línguas. Apesar de ter escrito um romance, novelas e crítica literária o autor é mais conhecido pelas suas incursões no gênero conto. Sua proposta estética minimalista explora os limites da escrita com o objetivo de expor o máximo de significado no mínimo de signos. 
Ao afirmar que para escrever o menor dos contos uma vida toda é pouco, o autor parece fazer coro aos valores defendidos por Nietzsche: demora, acúmulo, resistência a ação imediata, etc.

As experiências estéticas daltonianas, demonstram que todos os termos são absolutamente necessários na composição de um texto, não havendo desperdício de palavras. Seus contos se assemelham a aforismos, expressões que reverberam em significados. Frases curtas e objetivas, criando relatos precisos, sem se desviar do alvo. Tudo composto com exímia acuidade poética. Nada se perde nas suas tramas.

“Uma sanguessuga das gordas é o teu amor, grudada na minha nuca”. (TREVISAN, 2013. p. 60)

Podemos objetar que a frase acima se assemelhe a um conto, porém para o autor as palavras não devem ser desperdiçadas. As poucas palavras utilizadas multiplicam-se em significados.

Para interpretar esse conto se faz necessário agir tal qual Nietzsche nos aconselha para aprender a ver: refrear o ímpeto, abster-se de rapidamente compreender. O Conto está solto, não há personagens, diálogos ou contexto, para compreender precisamos criar, nos mover em direção ao texto. Eis um elemento de mestria o desafio e o convite.

A ausência de travessão denota que esta não é uma fala. Uma hipótese possível é que este é um pensamento, dada a sua estrutura conclusiva podemos especular que é um pensamento secreto, daqueles que surgem em momentos de intensa reflexão, mas que não podem ser explanados.

Em um movimento de introspecção, o possível personagem conclui sobre o amor que alguém sente por ele, devido ao uso do termo "teu" posso pressupor uma proximidade do agente do amor, mais um reforço para a hipótese de pensamento secreto.

A conclusão que não pode ser explicitada é desalentadora, a metáfora para o amor é a sanguessuga. Este pequeno ser que se alimenta da energia vital alheia. A capacidade de absorção de uma sanguessuga é muito maior que o seu volume. É desta forma que o personagem sente o amor do qual se é vítima, algo que suga sua energia vital, com uma capacidade de absorção quase ilimitada.

Outra característica das sanguessugas é sua capacidade de passarem despercebidas. Capazes de secretarem anticoagulante e anestésico no local no qual aderem, este pequeno vampiro faz com que os vasos sanguíneos se dilatem e o sangue flua da sua vítima para si de forma ininterrupta. Eis o amor, sem se fazer notar vorazmente devora sua vítima. 
Porém, esta não é uma simples sanguessuga, mas sim uma sanguessuga "das gordas", novamente precisamos nos demorar. $O$ autor não diz "uma sanguessuga gorda", mas sim uma "sanguessuga das gordas", a ênfase no adjetivo "gorda" remete a força metafórica para a palavra "gorda" e não apenas para o substantivo "sanguessuga".

A sanguessuga é gorda, pois está muito bem alimentada. Eis o desalento, este não é um amor recente ou um amor frívolo, ele é duradouro ou intenso, não há meio termo.

Depois de categorizado o amor, o personagem aponta a situação do mesmo, ele encontra-se grudado. Percorrendo a metáfora da sanguessuga este amor ainda está presente, ele não foi extirpado, sua ação persiste.

A localização da sanguessuga se harmoniza com o espírito do conto. A nuca, local não exposto a visão, mas de suma importância para o corpo, a ligação entre a cabeça e o coração, este amor doentio intermedia os sentimentos e a racionalidade.

Findo o conto, finda a interpretação? Não, fazendo jus ao seu papel de mestre, o conto fala de maneira abundante. Prossigo: a metáfora da sanguessuga gorda grudada na nuca, também remete a dificuldade de se livrar deste amor.

Qualquer tentativa de acabar com essa relação cobrará o preço de levar um pedaço da sua vítima. Pois enquanto a sanguessuga se alimenta, ela secreta anestésico e anticoagulante, ao ser retirada ela expõe a ferida aberta, levando consigo o sangue já sugado e sua vítima imediatamente se sente muito pior do que quando a sanguessuga agia.

Estará o personagem condenado a esse dilema? Viver com um amor que o suga ou livrar-se desse amor e padecer a ausência do mesmo?

Mais uma ação de mestria nos ensinando a pensar. O conteúdo é inesgotável, as interpretações pululam e um esforço é necessário para que o pensamento se naturalize, não se vulgarize tentando abordar um pretenso todo.

Como a literatura de Dalton Trevisan agiria como mestre nos persuadindo e desestabilizando valores anteriores ao contato com ela? Poderá nos ensinar a falar sem tagarelice e a escrever com sangue?

"Quem the dera o estilo do suicida no último bilhete" (p. 124).

É difícil discordar da assertiva acima. Que leitor não gostaria de ler obras no estilo do último bilhete do suicida? Este estilo é definitivo, tudo o que foi dito não poderá ser corrigido, a escrita se eternizou ao se findar o autor, não há espaço para novas escritas. Haverá estilo mais pungente? 
Além de persuasão, neste conto também observo uma desestabilização dos valores. Ao pensar o bilhete do suicida como estilo, deslocamos suas significações. Inicialmente o bilhete de um suicida é visto como um desalento, uma despedida ou até mesmo como um testamento, porém aqui se torna estilo, forma, linguagem. Escrever como um suicida em seu último bilhete remete a uma escolha artesanal das palavras, um desafio para a escrita.

Esta derradeira escrita certamente demonstrará as vivências mais intensas daquele que as escreveu. A partir do caráter performático da linguagem conseguimos transpor o estilo da escrita para a fala, seria possível falar no estilo de um bilhete de suicídio?

Certamente que essa fala não seria verborrágica. Não é possível tagarelar em um bilhete de suicídio. Seria uma fala como nos recomenda Nietzsche, uma fala que expressaria e demonstraria nossas vivências mais intimas.

Os exemplos são muitos de como Dalton nos ensina a ver, pensar, falar e escrever como recomenda Nietzsche, na impossibilidade de abordar todos, farei uso do pensamento enquanto dança e de forma esvoaçante tocarei levemente mais alguns recortes.

“- Não gosto de você, amor. Mas não fique triste: não gosto de ninguém. Nem de minha mãe eu gosto" (p. 119).

Neste conto o mestre exemplifica e demostra para potencializar os discípulos. Uma primeira assertiva "Não gosto de você", seca, intransigente, pouco palatável é tornada mais amena na continuidade "Não gosto de você, amor". Prossegue em uma tentativa de consolo, "Mas não fique triste". Falta algo neste alento, novamente a fala permanece no ar, sem sustentação, muito personalista, por isso avança em uma tentativa de generalizar, "Mas não fique triste: não gosto de ninguém".

Para finalizar o toque de mestre, o complemento que dá sentido ao todo "Nem de minha mãe eu gosto", o fim que remete ao início e intensifica as significações até aqui construídas.

"A chuva sovina conta e reconta suas moedas nas latas do quintal" (p. 77).

O mestre demonstra sua toda sua força plástica. Com palavras compõe um belo quadro, repleto harmoniosamente de descrições e juízos valorativos. Difícil vai ser ouvir uma gota de chuva em uma lata sem pensar nesta descrição, o mestre acompanhará o discípulo mesmo em sua ausência física.

“- Não fale, amor. Cada palavra, um beijo a menos”. (p. 62). 
A pontuação a cada duas ou três palavras, nos obriga a demorar, as poucas palavras soltas escondem o esforço de síntese que o conto. É uma fala transposta para a escrita, neste intercambiamento de suportes o estilo se mantém, atento aos períodos e ao tempo, difícil saber se é uma escrita expressando uma fala ou uma fala transposta para uma escrita.

Dalton conseguiu, a partir da sua obra é possível espiritualizar a vida e cultivar a nobreza de espírito.

\section{PODE A LITERATURA SER UM MESTRE?}

Finda a tessitura, o que me resta é amarrar algumas pontas soltas e testar o tamanho da minha linha guia...

Diante do exposto anteriormente penso que a literatura se apresenta como um mestre possível, porém não posso me furtar de enfrentar as críticas as pretensões desse mestre.

Uma das fontes mais profícuas da didática é o diálogo com o mestre. No diálogo o mestre corrige, exorta, elogia e incentiva o discípulo, como fica esse diálogo na literatura?

A disputa pela mestria da palavra escrita com a oralidade não é recente. $\mathrm{Na}$ Grécia Clás sica os sofistas liam para os seus alunos, não apenas obras de outros autores, mas também suas obras em uma antecipação dos nossos seminários. Os filósofos clássicos dirigiram duras críticas a essa confiança em uma autoridade inerte, essa mediação do ensino a partir de um instrumento tão mundano quanto a escrita.

"Gênio da escrita que é, Platão, em Fedro e na Sétima carta, advoga a oralidade. Somente a palavra dita cara a cara é capaz de evocar a verdade e, portanto, garantir o ensino honesto." (STEINER, 2018, p. 38).

A escrita trava, imobiliza o discurso, torna estático o jogo livre do pensamento, sacraliza uma autoridade artificial. "A palavra escrita não escuta o que diz o seu leitor. Não toma conhecimento de suas perguntas e objeções. Uma pessoa que fala pode corrigir-se a cada momento; ela é capaz de fazer retificar sua mensagem. O livro, não” (p. 39).

A crítica de Platão ao uso da escrita pelos sofistas vai além da simples natureza estanque da escrita, perpassando desde a teoria epistemológica platônica até mesmo a disputa política com os sofistas. Por isso a dificuldade de compreender a crítica platônica, nos termos atuais onde dissolvemos a ideia de verdade, honestidade, verdade, etc. 
Por outro lado, a crítica a natureza estanque e unilateral da escrita ainda permanece. A experiência humana com a leitura nunca demonstrou-se estanque, basta observar como os deuses falam a partir dos livros sagrados e como a exegese desses livros permite que doutrinas criadas a milhares de anos ainda hoje façam sentido.

Em última instância “[...] a leitura é a menos passiva das ações. É ela a força por trás da oralidade do magistério. A literatura não é menos formativa que a filosofia: a poesia provavelmente assinala o ponto mais elevado das possibilidades humanas" (p. 107).

\section{REFERÊNCIAS}

NIETZSCHE, Friedrich Wilhelm. Crepúsculo dos ídolos, ou, Como se filos ofa com um martelo. Tradução, notas e posfácio de Paulo César de Souza. São Paulo: Companhia de Bolso, 2017. 135 p.

Assim falou Zaratustra: um livro para todos e para ninguém. Tradução, notas e posfácio de Paulo César de Souza. São Paulo: Companhia das Letras, 2011. 359 p.

STEINER, George. Lições dos mestres. Trad.: Maria Alice Máximo. 3. ed. Rio de Janeiro: Record, 2018. 195p.

TREVISAN, Dalton. Ah, é? Ilust.: Poty. 3. ed. Rio de Janeiro: Record, 2013. 127 p. 


\section{RESUMO}

Partindo do diagnóstico nietzschiano das três tarefas para as quais necessitamos de mestres: "Deve-se aprender a ver, aprender a pensar, aprender a falar e escrever: o objetivo, nos três casos, é uma cultura nobre". Minha proposta é pensar a literatura como o mestre capaz de realizar essas três tarefas. Utilizando Steiner (2018) intento responder o que é um mestre? Para que precisamos de um mestre? E, quais as características de um mestre? Neste recorte elenco ações de mestria e verifico sua plausibilidade quando exercidas pela literatura. Para verificar minha hipótese de literatura enquanto mestre utilizo a obra $A h$, é? de Dalton Trevisan, observando suas potencialidades para as três tarefas de mestria: ensinar a ver - demorando o olhar e espiritualizando a vida; ensinar a pensar - para gestar os pensamentos como dança e por fim ensinar a falar e escrever - falar sem tagarelice, expressando as vivências mais íntimas e escrever visceralmente, com sangue e espírito. Penso que a literatura se apresenta como um mestre ao carregar consigo elementos de mestria, tais como: persuasão, provocação, transmissão, potencialização, autoridade, modelo, etc.

Palavras-chave: Mestre. Educação. Literatura. Filosofia.

\section{¿PUEDE LA LITERATURA SER UN MAESTRO?}

\section{RESUMEN}

A partir del diagnóstico nietzscheano de las tres tareas para las que necesitamos maestros: "Se debe aprender a ver, aprender a pensar, aprender a hablar y escribir: el objetivo, en los tres casos, es una cultura noble". Mi propuesta es pensar la literatura como el maestro capaz de realizar esas tres tareas. Utilizando Steiner (2018) intento responder lo que es un maestro? ¿Para qué necesitamos un maestro? ¿Y qué características de un maestro? En este recorte elenco acciones de maestría y verifico su plausibilidad cuando ejercidas por la literatura. Para comprobar mi hipótesis de literatura mientras maestro utilizo la obra $A h$, é? de Dalton Trevisan, observando sus potencialidades para las tres tareas de maestría: enseñar a ver - demorando la mirada y espiritualizando la vida; enseñar a pensar - para gestar los pensamientos como danza y por fin enseñar a hablar y escribir - hablar sin tagarelice, expresando las vivencias más íntimas y escribir visceralmente, con sangre y espíritu. Creo que la literatura se presenta como un maestro al llevar consigo elementos de maestría, tales como: persuasión, provocación, transmisión, potenciación, autoridad, modelo, etc.

Palabras clave: Maestro. La educación. Literatura. Filosofía.

\section{CAN LITERATURE BE A MASTER?}

\section{ABSTRACT}

Starting from the Nietzschean diagnosis the three tasks to which the needs of teachers: "In cases, it is a noble culture". My word is think a literature that the greater may be my three three tasks. Using Steiner (2018) I try to answer what is a master? Why do they need a master? And, what are the characteristics of a master? This clipping cast mastery actions and check their plausibility when pursued by literature. To see my story of literature as master I use a work $A h$, é? of Dalton Trevisan, observing their potentialities for the three tasks of mastery: teaching to see - to demoralize and spiritualize life; "Thinking, thinking and acting as a teacher of dance and expression", "without gossip", expressing as "living more" and "writing" viscerally, with blood and spirit. I believe that literature presents itself as a master in transmitting elements of mastery, such as: persuasion, provocation, transmission, empowerment, authority, model, etc.

Keywords: Master. Education. Literature. Philosophy.

Submetido em: 14 de outubro de 2018

Aprovado em: 30 de abril de 2019 